\title{
UVB and UVA radiation-mediated damage to isolated and cellular DNA*
}

\author{
Jean Cadet ${ }^{\ddagger}$, Sophie Courdavault, Jean-Luc Ravanat, and \\ Thierry Douki
}

\begin{abstract}
Laboratoire des Lésions des Acides Nucléiques, Service de Chimie Inorganique et Biologique, CEA/DSM/Département de Recherche Fondamentale sur la Matière Condensée, CEA/Grenoble, F-38054 Grenoble, France
\end{abstract}

\begin{abstract}
The effects of solar light on cellular DNA are mostly explained by both direct excitation of nucleobases and photosensitized reactions that are mediated by UVB and UVA radiation, respectively. A large body of information is now available on the main photodynamic reactions to DNA, which involve guanine as the preferential target of both one-electron oxidation and singlet oxygen oxidation, as the result of type I and type II mechanisms. Most of the final products of the photosensitized reactions of guanine base in isolated DNA have been characterized, and comprehensive mechanisms for their formation have been proposed. Further insights into the mechanisms of solar radiation-induced modifications within cellular DNA have been gained from accurate measurement of the main photoproducts using recently designed sensitive chromatographic and biochemical methods. Thus, the distribution pattern of the 12 possible bipyrimidine photoproducts has been shown to be similar in the DNA of UVB-irradiated rodent and human cells. Cyclobutyl pyrimidine dimers are also generated at di-thymine and thymine-cytosine sites within nuclear DNA upon exposure to UVA radiation as the likely result of triplet energy transfer. In addition, oxidative reactions that involved mostly singlet oxygen, and to a lesser extent, ${ }^{\circ} \mathrm{OH}$ radicals are also implicated, although less efficiently.
\end{abstract}

Keywords: UVB; UVA; photodynamic reactions; DNA; radiation-mediated damage.

\section{INTRODUCTION}

Solar radiation is implicated in the etiology of most human skin cancers, which include basocellular and squamous cell carcinoma as well as malignant melanoma [1]. Action spectra for mutagenicity and lethality of the UVB component $(280<\lambda<320 \mathrm{~nm})$ of solar radiation show a strong overlapping with the absorption features of DNA in human cells. Occurrence of tandem mutations at dicytosine sites in genes such as p53 of patients suffering from skin cancers may be considered as a molecular signature of the contribution of the UVB component of solar radiation. This may be explained in terms of formation of bipyrimidine photoproducts that consist mostly of cis-syn diastereomers of cyclobutadipyrimidines (CPDs) that result from initial UVB-mediated excitation of one pyrimidine base followed by a [2+2] cycloaddition with vicinal thymine or cytosine (Fig. 1). Another competitive pathway that overall occurs with a lower efficiency and whose relative importance is also strongly sequence-de-

\footnotetext{
*Paper based on a presentation at the XX ${ }^{\text {th }}$ IUPAC Symposium on Photochemistry, 17-22 July 2004, Granada, Spain. Other presentations are published in this issue, pp. 925-1085.

¥Corresponding author
} 


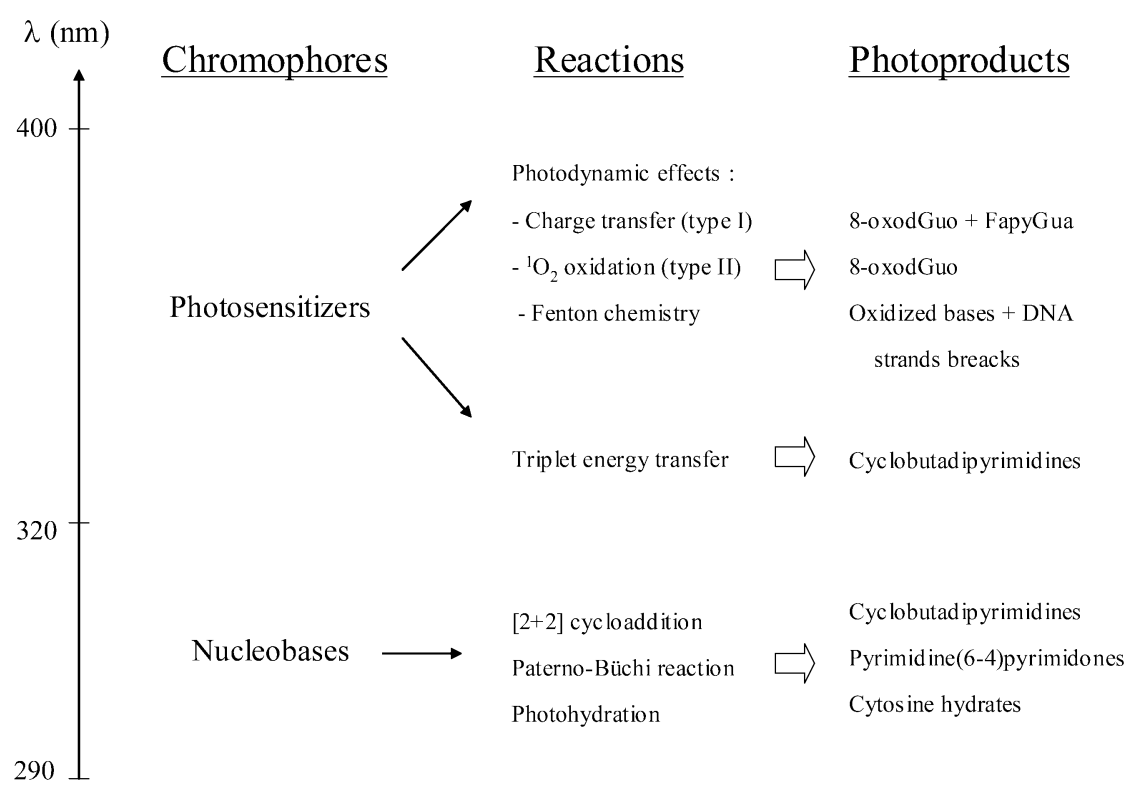

Fig. 1 Effects of solar radiation on cellular DNA involving direct excitation of DNA bases by the UVB component and photosensitized reactions mediated by the UVA component.

pendent is the Paterno-Büchi photoreaction. This involves the transient formation of highly unstable oxetanes or azetidines that implicates a singlet excited-state pyrimidine and that leads to the generation of pyrimidine(6-4)pyrimidone photoadducts (6-4PPs). The latter photoproducts that exhibit strong absorption features in the near-UV range may be converted into the related Dewar valence isomers (DewPPs) through secondary photochemical processes at biological relevant doses. Four main bipyrimidine sites that involve thymine and/or cytosine are present in DNA. Therefore, 12 possible photoproducts, most of them having been characterized in numerous model studies, are expected to be generated in UVB-irradiated isolated or cellular DNA $[2,3]$. Until recently, only a paucity of information was available on the UVB-induced formation of each of the pyrimidine photoproducts in DNA due to the lack of appropriate methods.

DNA bases do not absorb, at least significantly, in the UVA range $(320<\lambda<400 \mathrm{~nm})$ of the solar spectrum, whereas mutagenic effects are still present. The observation of the latter biological effects is strongly indicative of the occurrence of photosensitized reactions that, at least for some of them, are oxygen-dependent in terms of biological consequences. This contrasts with the UVB-mediated photobiochemical reactions that for the bulk are not affected by the presence of oxygen. Indication that 8-oxo7,8-dihydro-2'-deoxyguanosine (8-oxodGuo), an ubiquitous oxidation product of 2'-deoxyguanosine, is formed in the DNA of UVA-irradiated cells has been provided in several earlier publications $[4,5]$. However, only a paucity of information was available on the mechanism(s) involved in the UVA-mediated oxidation reactions of DNA. In that respect, the so-called photodynamic effects may be rationalized in terms of type I and type II photosensitization reactions that involve one-electron oxidation processes and singlet oxygen $\left({ }^{1} \mathrm{O}_{2}\right.$ ), respectively (Fig. 1). It should be added that superoxide radical $\left(\mathrm{O}_{2}{ }^{-}\right)$may be generated as a side product of the oxidation of the type I mechanism as the result of the induction of the radical anion of the photosensitizer. Subsequently, dismutation of $\mathrm{O}_{2}{ }^{-}$is expected to give rise to $\mathrm{H}_{2} \mathrm{O}_{2}$, a key reagent together with reduced transition metals of the Fenton reaction that may lead to the generation of the highly reactive ${ }^{\circ} \mathrm{OH}$ radical. Recent progress has been achieved for a better understanding of the main oxidation reactions of guanine, the main target of UVA-mediated photooxidation reactions [6,7]. In addition, CPDs are generated upon UVA irradiation of cellular DNA as the likely result of a triplet energy-transfer mechanism. In this short survey, emphasis is placed on recent 
aspects of type I- and type II-mediated photosensitized reactions of the guanine moiety of DNA and model compounds. In addition, relevant information is provided on the assessment of the main bipyrimidine photoproducts and oxidative damage that are generated within DNA upon exposure to UVB and/or UVA radiations using accurate chromatographic and biochemical methods of measurement.

\section{PHOTOSENSITIZATION REACTIONS OF THE GUANINE MOIETY OF ISOLATED AND CELLULAR DNA}

\section{One-electron oxidation reactions}

Guanine that shows the lowest ionization potential among the DNA constituents [8], including normal nucleobases and 2-deoxyribose, is the preferential target of most one-electron oxidation by chemical and physical agents [6,7]. In most cases, type I photosensitization reaction may be rationalized in terms of electron transfer between guanine and the photosensitizer, likely in a triplet excited state, giving rise to an unstable purine radical cation. The latter species may also be generated indirectly as the result of charge-transfer processes from positive holes produced by one-electron oxidation of the pyrimidine bases and adenine. Several mechanisms that include hopping, phonon-assisted polaron-like hopping, and/or coherent super-exchange have been proposed to explain the hole migration process [9]. The guanine radical cation is expected to undergo two competitive reactions in aqueous solutions, namely, deprotonation and hydration (Fig. 2), whose relative importance depends on several parameters including the DNA structure and $\mathrm{pH}$.<smiles>CN1C=NC2C(=O)NC(N)=NC21O</smiles><smiles>O=C(O)O</smiles><smiles></smiles><smiles>Cn1cnc2c(=O)[nH]c(N)nc21</smiles><smiles>CCCCO</smiles><smiles>CN1c2nc(N)[nH]c(=O)c2NC1O</smiles>

Fig. 2 Generation of the guanine radical cation and of the subsequent neutral radicals that may be also produced by ${ }^{\circ} \mathrm{OH}$ radical.

Hydration of the guanine radical cation [10] occurs with a pseudo-first-order rate constant estimated to be $6 \times 10^{4} \mathrm{~s}^{-1}$ within double-stranded DNA [11] giving rise to 8-hydroxy-7,8-dihydroguanyl radical (Fig. 2). The latter reducing purine radical that may be also generated by the addition of ${ }^{\circ} \mathrm{OH}$ at $\mathrm{C} 8$ of the guanine moiety in $17 \%$ yield [12] is converted into final decomposition products through two competitive pathways. Oxidation that is favored by the presence of molecular oxygen leads to the formation of ubiquitous 8-oxo-7,8-dihydroguanine (8-oxoGua) that is used as a biomarker of exposure to oxidative agents. On the other hand, reduction of the 8-yl radical that has been shown to occur within isolated DNA as a relatively minor process in aerated aqueous solution gives rise to 2,6-diamino-4-hydroxy-5-formamidopyrimidine [13], the so-called FapyGua compound. This is accounted for, following 
the reduction step, by the cleavage of the C8-N9 bond of the imidazole ring of guanine with an efficient rate $\left(k=2 \times 10^{5} \mathrm{~s}^{-1}\right)$ that was determined by pulse radiolysis measurements [14]. Interestingly, both 8-oxoGua and FapyGua have been shown to be generated within cellular DNA upon exposure to ionizing radiation according to mechanisms that may involve ${ }^{\circ} \mathrm{OH}$ radical and one-electron oxidation [15].

Deprotonation of the guanine radical cation that exhibits a $\mathrm{p} K$ a value of 3.9 is an efficient process in isolated nucleosides and singled-stranded DNA [14]. This leads to the formation of a highly oxidizing radical that may be also generated by dehydration of the overwhelming ${ }^{\circ} \mathrm{OH}$ radical adduct at $\mathrm{C} 4$ of the purine ring that takes place with a measured rate of $k=6 \times 10^{3} \mathrm{~s}^{-1}$ [14]. The two main final decomposition products of transient $\mathrm{G}(-\mathrm{H})^{\cdot}$ that may exist in several tautomeric forms, including the 6-oxyl and the $\mathrm{C} 5$ carbon-centered radicals, have been identified as 2,2,4-triamino-5(2H)-oxazolone ( $\mathrm{Z}$ ) and its labile 2,5-diamino-4H-imidazol-4-one (Iz) precursor [16]. Addition of $\mathrm{O}_{2}$ to the $\mathrm{C} 5$ carbon of $\mathrm{G}(-\mathrm{H})^{\circ}$, despite the fact that the rate of the reaction has been estimated to be very slow, has been postulated to lead to the transient formation of peroxyl radical. Another possibility would be the addition of superoxide radical $\left(\mathrm{O}_{2}{ }^{-}\right)$through the reaction with $\mathrm{G}(-\mathrm{H})^{\cdot}$ whose rate constant has been estimated to be $3 \times 10^{9} \mathrm{M}^{-1} \mathrm{~s}^{-1}$ for the $2^{\prime}$-deoxyribonucleoside [14]. The rate of the reaction is, however, lower when $\mathrm{G}(-\mathrm{H})^{*}$ is generated within dGMP [17] and short oligonucleotides [18], the $k$ values being $1.3 \times 10^{9}$ and $0.47 \times 10^{9} \mathrm{M}^{-1} \mathrm{~s}^{-1}$, respectively. A rather complicated decomposition pathway has been proposed to explain the formation of Iz following the transient formation of 5-hydroperoxide and/or related peroxyl radical (Fig. 3). This involves the opening of the pyrimidine at the C5-C6 bond with subsequent decarboxylation that is accompanied by hydration of the 7,8 double bond. Then, the carbinolamine thus generated, is likely to undergo ring-chain tautomerism that leads to opening of the imidazole ring with the release of formylamine [19]. Subsequent intramolecular cyclization of the guanidine substituent of the resulting intermediate would give rise to Iz. As a further complication, Iz, whose half-life was estimated to be of $10 \mathrm{~h}$ for the related 2'-deoxyribonucleoside derivative in aqueous solution at $20^{\circ} \mathrm{C}$, is quantitatively converted to $\mathrm{Z}$ by hydrolysis [16]. The very low yield of 8-oxo7,8-dihydro-2'-deoxyguanosine (8-oxodGuo) that is present in aerated aqueous solutions of 2'-deoxyguanosine (dGuo) that has been exposed to oxidation reactions mediated either by ${ }^{\circ} \mathrm{OH}$ radical or excited type I photosensitizer such as riboflavin is not explained only by the low efficiency of the hydration process of the guanine radical cation with respect to the deprotonation reaction. In fact, it was shown that 8-oxodGuo is consumed as soon as it is produced in a reaction with the overwhelming oxidizing $\mathrm{G}(-\mathrm{H})^{*}$ radical (Fig. 4), giving rise predominantly to a spiroiminodihydantoin nucleoside (dSp) together with $\mathrm{Iz}$ and $\mathrm{Z}$, generated in lower amounts [20]. The rate constant of the reaction of $\mathrm{G}(-\mathrm{H})^{\circ}$ with 8-oxodGuo was found to be $0.46 \mathrm{M}^{-1} \mathrm{~s}^{-1}$ at $\mathrm{pH} 7$ [21]. In contrast, 8-oxodGuo is formed pre-<smiles>C=CC=C</smiles>

$\mathbf{G}(-\mathbf{H})^{\circ}$<smiles>CNC1=NC(N)(N)OC1=O</smiles><smiles>CN1C=NC2C(=O)N=C(N)N=C21</smiles><smiles>CN1C=NC2(OO)C(=O)N=C(N)N=C12</smiles><smiles>CN1C=NC(=O)/C1=N/C(=N)N</smiles><smiles>CO</smiles>
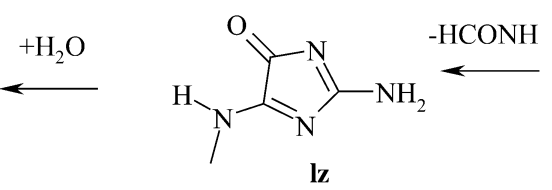<smiles>CN1/C(=N/C(=N)N)C(=O)NC1O</smiles>

Fig. 3 Hydration of the guanine radical cation: further chemical reactions. 


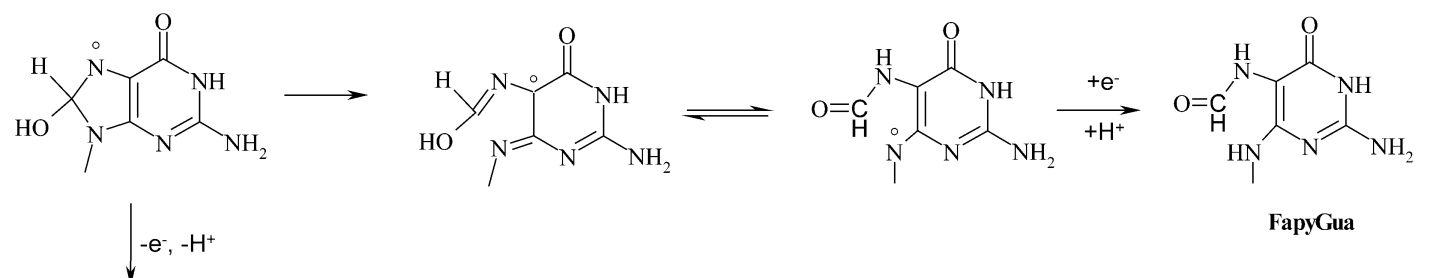

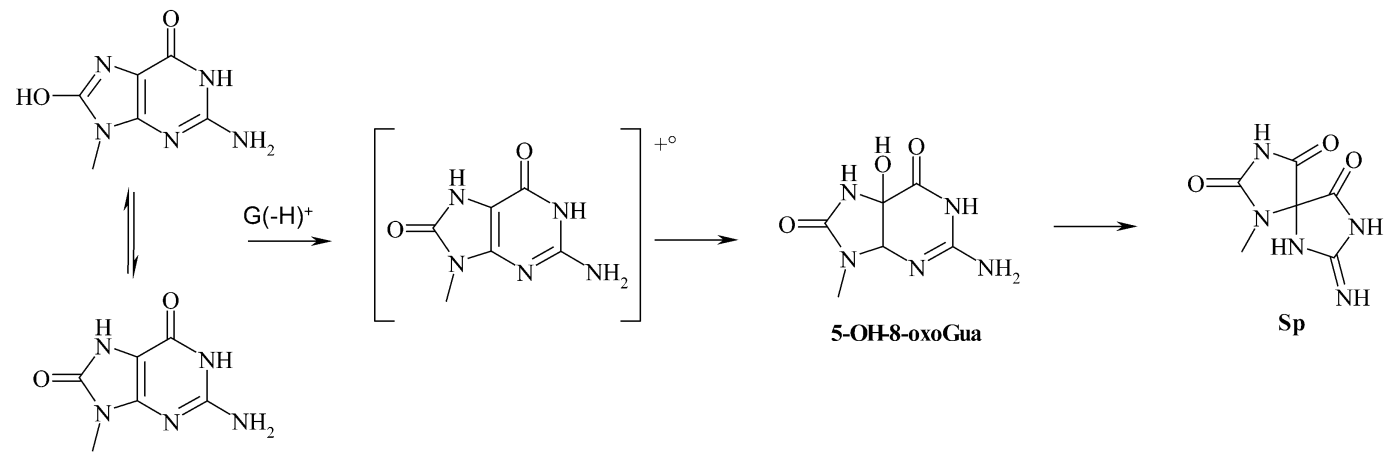

Fig. 4 Deprotonation of the guanine radical cation: further chemical reactions.

dominantly within double-stranded DNA under the above oxidation conditions. This may be rationalized both in terms of a rather inefficient $\mathrm{G}(-\mathrm{H})^{\circ}$-mediated oxidation of 8-oxodGuo in the DNA chain and a stabilization of the guanine radical cation through base stacking and base pairing that makes deprotonation less prominent.

\section{Singlet oxygen oxidation of the guanine moiety of DNA and model compounds}

Guanine is the exclusive DNA component that reacts in aqueous solutions at neutral $\mathrm{pH}$ with ${ }^{1} \mathrm{O}_{2}$ in the ${ }^{1} \Delta_{\mathrm{g}}$ state $(\mathrm{E}=22.4 \mathrm{kcal} / \mathrm{mol})$ [6]. A predominant Diels-Alder [4 +2] cycloaddition across the 4,8-bond of the imidazole ring of the guanine moiety of dGuo appears likely to give rise to unstable diastereoisomeric 4,8-endoperoxides (Fig. 5). Support for this mechanism was provided by the NMR characterization at low temperature in an organic solvent of the 4,8-endoperoxides that were produced by tetraphenylporphyrin-mediated photosensitization of 2',3',5'-O-tert-butyldimethylsilyl-8-methylguanosine as the result of ${ }^{1} \mathrm{O}_{2}$ oxidation [22]. The main stable degradation products of dGuo and guanosine were characterized as the two diastereomers of related nucleoside derivatives of spiroiminodihydantoin (Sp) $[23,24]$, the main one-electron oxidation products of 8-oxodGuo $[20,24]$ and 8-oxo-7,8-dihydroguanosine $[25,26]$, respectively. A likely mechanism to explain the formation of the latter purine rearrangement nucleosides would involve in the first step conversion of the 4,8-endoperoxides into 8-hydroperoxy-2'-deoxyguanosine. Subsequently, loss of a water molecule from the peroxide function is expected to generate an oxidized quinonoid intermediate whose C5-N7 double bond is highly susceptible to nucleophilic addition [27]. Addition of a water molecule is excepted to lead to unstable 5-hydroxy-8-oxo-7,8-dihydro-2'-deoxyguanosine, which is known to give rise predominantly through an acyl shift to $\mathrm{dSp}$ in aqueous solutions at $\mathrm{pH} \geq 7$. A competitive reduction of 8-OOHdGuo would explain the formation of 8 -oxodGuo that is generated in about $1 / 3$ yield of the spiroiminodihydantoin nucleosides [28]. Interestingly, the presence of reducing agents such as thiols and $\mathrm{Fe}^{2+}$ ions in the photosensitized solutions of either dGuo or Guo leads to the predominant formation of 8-oxodGuo and related ribonucleoside [23], which occurs at the expense of the spiroiminodihydantoin nucleosides. A simplified degradation pattern is observed for the ${ }^{1} \mathrm{O}_{2}$-mediated oxidation reaction of the guanine moiety within double-stranded DNA [29]. Thus, only the formation of 8-oxodGuo is observed upon expo- 


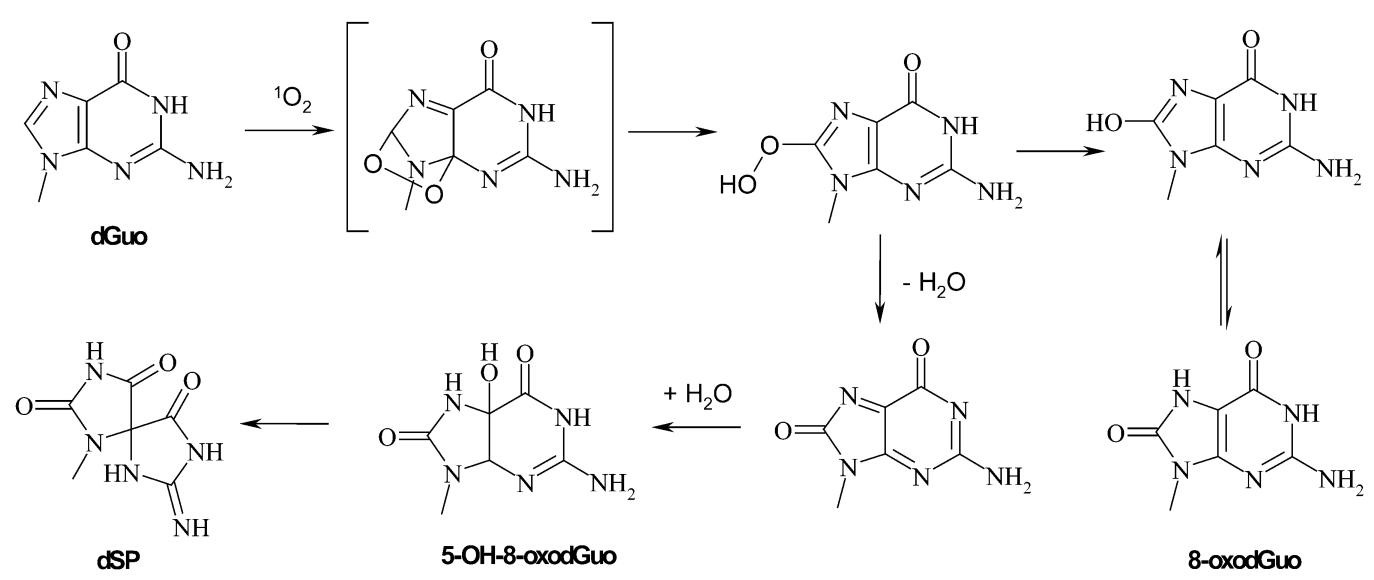

Fig. 5 Singlet oxygen oxidation of the guanine base.

sure of calf thymus DNA to a chemical source of ${ }^{1} \mathrm{O}_{2}$ provided by the thermodissociation of naphthalene endoperoxide [30]. The reasons for the observed high specificity in the ${ }^{1} \mathrm{O}_{2}$ oxidation of the guanine moiety of DNA that still required to be elucidated could be related to steric factors and/or the presence of reducing agents. The lack of formation of FapyGua is a clear indication of the fact that ${ }^{1} \mathrm{O}_{2}$ is not able to act on guanine by charge-transfer reaction in contrast to a previous suggestion [31].

Interesting insights into the chemical reactions mediated by ${ }^{1} \mathrm{O}_{2}$ with cellular DNA were gained from experiments performed on a human lymphocyte cell line using a suitable thermolabile endoperoxide [30], which allows the release of $\left[{ }^{18} \mathrm{O}\right]$-labeled singlet oxygen in the close vicinity of the nucleus. Thus, the observed formation of $\left[{ }^{18} \mathrm{O}\right]-8$-oxodGuo that was inferred from HPLC-MS/MS measurements clearly demonstrated that ${ }^{1} \mathrm{O}_{2}$, and not an indirectly mediated oxidative process, was involved in the formation of 8-oxodGuo [32]. It was also recently found using the enzymatic modified version of the comet assay that chemically generated ${ }^{1} \mathrm{O}_{2}$ is able to induce only a very few DNA strand breaks with respect to the amount of 8-oxodGuo that was revealed as formamidopyrimidine DNA $\mathrm{N}$-glycosylase (Fpg) sites [33].

\section{FORMATION OF BIPYRIMIDINE PHOTOPRODUCTS WITHIN CELLULAR DNA}

Relevant information on the distribution pattern of the bipyrimidine photoproducts that are the main lesions (Fig. 6) induced by either UVB or UVA photons within cellular DNA relies on the availability of accurate, specific, and quantitative methods. The use of chromatographic methods such as thin-layer and HPLC has been hampered by the requirement of DNA prelabeling with radioactive isotope [2], which seriously limits applications. It should be added that the usual acidic treatment applied to release the bases prior to chromatographic analysis would prevent quantification of the brittle DewarPPs. Immunodetection of bipyrimidine damage, even if relatively specific mono- and polyclonal antibodies are available [34], does not allow individual measurement of dedicated damage and often suffers from a lack of calibration. These difficulties have been mostly overcome due to the recent availability of the accurate and sensitive HPLC-MS/MS method operating in the electrospray ionization (ESI) that has already also received interesting applications with the measurement of oxidized nucleosides in cellular DNA [6]. Typically, the initial step of the assay involves enzymic digestion of DNA [35] after its extraction from UV-irradiated cells. This is achieved using a mixture of enzymes that include 3'- and 5'-exonucleases, once a quantitative conversion of Cyt containing Pyr $<>$ Pyrs and 5'-end cytosine 6-4PPs into the corresponding uracil derivatives through deamination of the 5,6-dihydrocytosine moieties has been achieved. The resulting mixture of bipyrimidine photoproducts that are released as modified dinucleoside monophosphates can be analyzed by HPLC-MS/MS. Thus, this allows complete sep- 

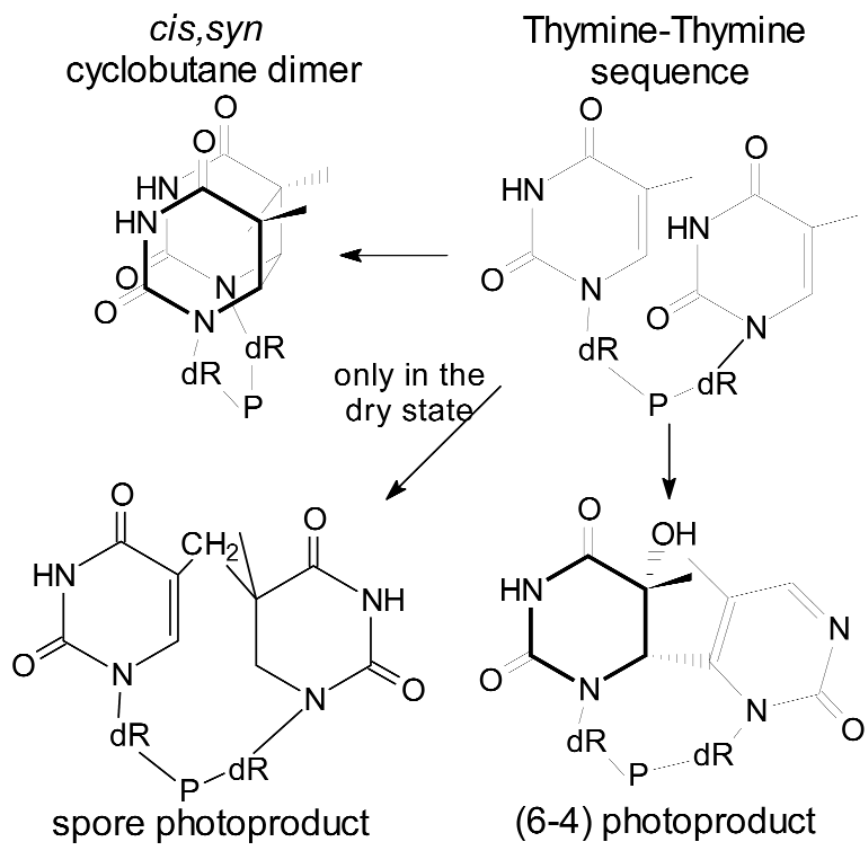

Fig. 6 Structure of UVC- and UVB-induced thymine dimeric photoproducts (dR: 2-deoxyribose, P: phosphate). The absolute stereoconfiguration of the spore photoproducts produced within cellular DNA remains to be determined.

aration and accurate detection of the 12 possible bipyrimidine adducts at TT, TC, CT, and CC. The high sensitivity of the tandem MS detection technique when used in the multiple reaction monitoring (MRM) mode is illustrated by the precise measurement of the main bipyrimidine photoproducts in isolated and cellular DNA upon exposure to low doses of UVC and UVB radiation [36,37]. Another interesting feature of the MRM detection mode is that it provides a specific way of differentiating CPD from 6-4PP for a given bipyrimidine sequence that exhibits the same molecular weight, taking advantage of the occurrence of different fragmentation patterns [38]. Recent extension of the HPLC-MS/MS assay has been made for measuring 5,6-dihydro-5-( $\alpha$-thyminyl)thymine, the so-called "spore photoproduct", a fourth type of thymine dimeric photoproduct that is predominantly generated upon UVC irradiation of DNA as a dry film. The photoreaction leading to the formation of "spore photoproduct" in dry DNA is highly stereospecific since only one of the two possible diastereomers was found to be generated [39]. Further application of this relevant method would focus on the determination of the distribution pattern of bipyrimidine photoproducts, including 5,6-dihydro-5-( $\alpha$-thyminyl)thymine in the DNA of anhydrous microorganisms following UVC and vacuum solar irradiation.

\section{UVB radiation}

Application of the recently designed HPLC-MS/MS assay has thus allowed the determination of a complete distribution pattern of UVB-induced dimeric pyrimidine photoproducts in cellular DNA. Initially, the formation of dimeric photoproducts at dithymine sites was determined in the DNA of UVB-irradiated THP1 human monocytes within the dose range $\left(0-600 \mathrm{~J} \mathrm{~m}^{-2}\right)$ [36]. Interestingly, the conditions of low dose exposure that were used were found to minimize the occurrence of secondary photoreactions such as photoreversion of CPDs and photoisomerization of 6-4PPs. The measurements have been extended to photolesions at other bipyrimidine sites, including TC, CT, and CC [37]. A strong primary sequence dependence on bipyrimidine photoproduct formation was observed, the importance of the three main photoproducts decreasing in the following order: cis-syn Thy $<>$ Thy $>6-4 \mathrm{PP}$ at TC sequence $>$ 
Thy $<>$ Cyt $>6-4 \mathrm{PP}$ at TT sequence. It may be noted that CPDs and 6-4PPs are produced with a much lower efficiency at CT, and to a smaller extent, at CC sites, suggesting a low photoreactivity of the bases involved in these sequences. Another interesting feature deals with the almost complete lack of formation of the Dewar valence isomers of 6-4PPs with only traces at CC sites upon exposure of cellular DNA to biologically relevant doses of UVB radiation [37]. A similar strong primary sequence effect on the formation of bipyrimidine photoproducts has been also observed upon UVC irradiation of human monocytes [36], suggesting the lack of significant specific effects of any wavelength within the range 250-320 $\mathrm{nm}$. The degradation pattern is also similar in the DNA of human fibroblasts [40] and CHO cells [41] upon exposure to UVB radiation (Table 1). Finally, it may be emphasized that the cellular content does not exert any modulating effect on the relative formation of UVB bipyrimidine photoproducts as inferred from the comparison of the photoproduct distribution with that measured in naked DNA [36].

Table 1 Yields of bipyrimidine photoproduct formation in the DNA of Chinese ovary cells following exposure to UVB, UVA radiation and solar simulated light (SSL) using HPLC-MS/MS measurements (from [41]).

\begin{tabular}{|c|c|c|c|}
\hline & $\mathrm{UVB}^{\mathrm{a}}$ & $\mathrm{UVA}^{\mathrm{b}}$ & $\mathrm{SSL}^{\mathrm{c}}$ \\
\hline Thy<> Thy & $17.51 \pm 1.24$ & $19.15 \pm 3.71$ & $15.86 \pm 1.81$ \\
\hline $6-4 \mathrm{TT}$ & $1.66 \pm 0.13$ & n.d. ${ }^{\mathrm{d}}$ & $0.09 \pm 0.05$ \\
\hline DewarTT & n.d. ${ }^{\mathrm{d}}$ & n.d. ${ }^{\mathrm{d}}$ & $0.87 \pm 0.23$ \\
\hline Thy $<>$ Cyt & $13.90 \pm 2.16$ & $1.19 \pm 0.11$ & $6.19 \pm 1.05$ \\
\hline $6-4 \mathrm{TC}$ & $14.33 \pm 1.60$ & n.d. ${ }^{\mathrm{d}}$ & $2.05 \pm 0.53$ \\
\hline DewarTC & n.d. ${ }^{\mathrm{d}}$ & n.d. ${ }^{\mathrm{d}}$ & $3.72 \pm 0.36$ \\
\hline $\mathrm{Cyt}<>\mathrm{Cyt}$ & $1.19 \pm 0.29$ & $0.09 \pm 0.06$ & $0.62 \pm 0.07$ \\
\hline
\end{tabular}

aYields are reported in lesions per $10^{9}$ bases and per $\mathrm{J} \mathrm{m}^{-2}$

b,c Yields are reported in lesions per $10^{9}$ bases and per $\mathrm{kJ} \mathrm{m}^{-2}$

${ }^{d}$ n.d.: not detectable.

Attempts were made in recent theoretical studies to provide an explanation for the observed large differences in photoreactivity of bipyrimidine sites. This was achieved using a novel density functional theory approach on the basis of the comparison of the properties of the base in their singlet excited states [42]. The main conclusions are that in agreement with HPLC-MS/MS measurement [36,37], CPDs are expected to be preferentially formed at TT and TC clusters, whereas CC and CT bipyrimidine sites exhibit poor photoreactivity. However, CC photoproducts, although generated in low yields, are highly mutagenic as inferred from the observation of a tandem mutation CC $\rightarrow$ TT that is used as a molecular signature of UVB radiation exposure. It is clear, however, that the determination of the nature of the highly mutagenic UVB-induced photolesion(s) responsible for these mutational events is awaiting further experiments.

6-Hydroxy-5,6-dihydrocytosine, the so-called "cytosine photohydrate", which is formed by hydration of cytosine (Fig. 7) upon excitation to a singlet state is another putative UVB-induced DNA photoproduct [2]. However, despite the interest for the "cytosine photohydrate", there was still a paucity of information on the efficiency of the photoinduced formation of this lesion in both isolated and cellular DNA. A relevant assay that allows the measurement of the targeted lesion as the $6 R$ and $6 S$ diastereomers of 6-hydroxy-5,6-dihydro-2'-deoxyuridine upon DNA enzymatic hydrolysis and quantitative deamination is now available [43]. It was found that the formation of cytosine hydrate in isolated DNA upon UVC irradiation is a minor event since it represents about $1 \%$ of that of the induction of overall CPDs. The photohydration of cytosine occurs with a lower efficiency in cellular DNA as inferred from the assessment of the yield of cytosine photohydrates, which is three orders of magnitude 


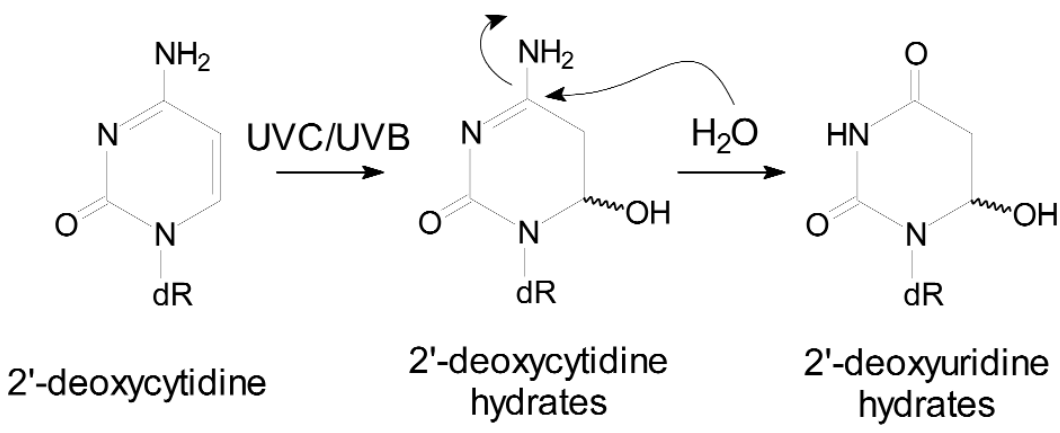

Fig. 7 Photohydration of 2'-deoxycytidine and deamination of the resulting cytosine photohydrates.

lower than that of CPDs. The latter observed decrease in the efficiency of cytosine photohydration may be accounted for by lower accessibility of water molecules of the cytosine moieties in compacted cellular DNA.

\section{UVA radiation}

The first observation showing that UVA is able to generate CPDs in cellular DNA was made on bacteria [44]. This is not restricted to prokaryotic cells since the UVA-mediated formation of CPDs has been also found to occur in mammalian cells. For this purpose, various methods were applied, including immunoassays [45], the modified alkaline elution technique [46], the ligation-mediated polymerase chain reaction (LM-PCR) assay [47] and the gel electrophoresis analysis [48] that has involved the use of either T4 endonuclease V or UV endonuclease to reveal CPDs. Evidence for the UVA-induced formation of CPDs in the DNA of human skin was gained from the results of immunohistochemical studies [49]. Application of the HPLC-MS/MS assay designed for the measurement of bipyrimidine lesions assay has provided a clear qualitative and quantitative picture of the photoproduct spectrum generated upon UVA irradiation of CHO cells [41]. Thus, cis-syn Thy $<>$ Thy was found to be the predominant photoproduct while cis-syn Thy $<>$ Cyt and $\mathrm{Cyt}<>$ Thy were generated in lower yields (Table 1). Another relevant observation that has major mechanistic insight (vide infra) deals with the complete lack of 6-4PPs and DewPPs formation as already noticed in the DNA of UVA-irradiated CHO cells on the basis of immunological measurements [45]. The exclusive UVA-mediated formation of CPDs is likely to be explained in terms of a triplet energy-transfer mechanism, mostly due to the fact that the absence of 6-4PPs and/or Dewar valence isomers is not compatible with a singlet excitation process [2]. Further support for the implication of triplet energy-transfer mechanism to explain the UVA-induced formation of CPDs came from the observation of a similar distribution pattern of bipyrimidine photoproducts in calf thymus DNA using acetophenone and benzophenone as the photosensitizers. However, the exact mechanism of UVA-sensitized formation of CPDs, which should include characterization of the endogenous photosensitizer(s) remains to be established. It may be added that the contribution of the most energetic UVA photons to direct excitation of the pyrimidine bases should be, at the best, a minor process. Another major point that has to be emphasized deals with the fact that UVA photons are about three-fold less efficient in generating CPDs than 8-oxodGuo (vide infra) in the DNA of Chinese hamster ovary cells [5,41]. Similar observations were made in terms of the formation of CPDs and 8-oxodGuo in UVA-irradiated normal human skin cells [50].

\section{Combined effects of UVB and UVA radiation}

HPLC-MS/MS measurements were also used to monitor the formation of bipyrimidine photoproducts in the DNA of CHO cells upon exposure to solar simulated light (SSL) and the results are reported in 
Table 1. Thus, it was found that cis-syn Thy $<>$ Thy and, to a lesser extent, cis-syn Thy $<>C y t$ are predominantly formed in CHO cells [41] in agreement with similar observations that were made using immunological [45] and LM-PCR [47] methods. However, it is clear that the presence of UVA radiation in SSL has a modulating action on the bipyrimidine photoproduct distribution pattern. Thus, we may note that cis-syn Thy $<>$ Cyt is now more abundant than related 6-4PPs in contrast to what was observed after UVB irradiation alone [41]. The relative decrease in TT and TC 6-4PPs is compensated by the formation of the corresponding valence Dewar isomers as the result of efficient UVA-mediated photoisomerization (Fig. 8). Further support for the significant involvement of UVA to promote secondary reactions was provided by the observation of predominant conversion of initially UVB-induced 6-4PPs at TC and TT sites into related Dewar valence isomers within the DNA of human keratinocytes. It remains now to establish the biological significance of the indirect formation of DewPPs in the DNA of UVA-irradiated cells. Another contribution of UVA radiation to the photochemical effects of SSL deals with the photosensitized formation of CPDs and more precisely of cis-syn Thy $<>$ Thy as already discussed (vide supra). It is likely that the SSL-mediated formation of 8-oxodGuo that has been measured in the DNA of CHO cells is mostly explained in terms of sensitized oxidation reactions to UVA [5].

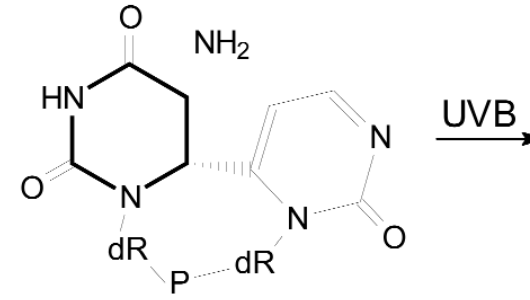

(6-4) photoproduct

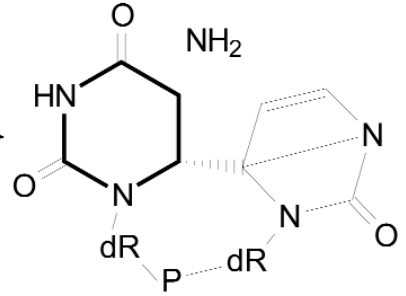

Dewar valence isomer

Fig. 8 Photoisomerization of 6-4PPs at TC sites into the corresponding Dewar valence isomer.

\section{PHOTOINDUCED OXIDATIVE REACTIONS OF CELLULAR DNA}

\section{UVB radiation-mediated formation of 8-oxodGuo}

Several independent studies have concurred with the fact that UVB has the capability to induce the formation of 8-oxodGuo in the DNA of mouse epidermis [51], mouse keratinocytes [52,53], and Chinese hamster ovary cells [5]. However, the mechanism of this photooxidation reaction that is of low amplitude with respect to bipyrimidine photoproduct formation remains for the bulk unclear since 8-oxodGuo may by generated by a broad range of oxidants. In that respect, it has been proposed that ${ }^{\circ} \mathrm{OH}$ radical [53] could be implicated in the oxidation of the guanine base on the basis of the observation that UVB is able to induce DNA strand breaks. Singlet oxygen has also been shown to specifically generate 8 -oxodGuo in both isolated and cellular DNA [6,29,32]. It may be added that evidence was provided that, at least in model studies, ${ }^{1} \mathrm{O}_{2}$ is produced in reaction of molecular oxygen with triplet excited purine and pyrimidine bases [54]. A third mechanism to be considered would be the occurrence of charge-transfer reaction involving purine and pyrimidine bases that may lead to one-electron oxidation of the guanine moiety of DNA [6,7] with the subsequent formation of 8-oxodGuo. If this is the case, FapyGua should be produced from the likely 8-hydroxy-7,8-dihydroguanyl radical that may also be generated by ${ }^{\circ} \mathrm{OH}$ radical. Further work is required on the basis of measurement of final oxidation products than should include 8-oxodGuo, FapyGua, and strand breaks in order to gain further insights into the mechanism of UVB-induced formation of 8-oxodGuo within cellular DNA. 


\section{UVA-mediated photooxidation reactions}

The biological effects of UVA radiation alone are not as clear as those induced by UVB photons. This is illustrated, for example, by the fact that UVA radiation is a rather mild and aspecific mutagen. This contrasts with UVB radiation, which is known to induce a characteristic mutation fingerprint at bipyrimidine sites including TC and CC sequences [55]. Besides the UVA-induced formation of CPDs, several lines of evidence are now available showing that cellular DNA may be damaged by photosensitized oxidation reactions [for a recent review, see 56]. More direct proofs for the occurrence of oxidative processes in the DNA of UVA-irradiated human and CHO cells were provided by the measurement of an increased-level of 8-oxodGuo in nuclear DNA and RNA [4,5]. Additional information on the formation of several classes of oxidative damage induced by UVA and visible radiation to cellular DNA was obtained from measurements achieved using a modified alkaline elution technique [46,57]. More recently, a detailed study that was aimed at gaining further mechanistic insights into the UVA-induced oxidative damage to cellular DNA was designed. This has involved a comparison of the molecular effects of UVA radiation on the DNA of human monocytes with those provided by ionizing radiation, in other words, mostly ${ }^{\circ} \mathrm{OH}$ radical [58]. Thus, UVA-induced induction of 8-oxodGuo was found to be linear with the applied doses within the dose range $0-150 \mathrm{~kJ} \mathrm{~m}^{-2}$ using an HPLC-electrochemical detection assay whereas the formation of three main classes of oxidatively generated damage to DNA was quantified using a modified comet assay [58]. These include frank DNA strand breaks together with alkali-labile lesions, whereas additional nicks were revealed by incubation with formamidopyrimidine DNA glycosylase (Fpg) and endonuclease III (endo III) enzymes, respectively. Thus, it was found that the level of Fpg-sensitive sites was much higher than that of either strand breaks or lesions excised by endo III (Table 2). This in agreement with similar conclusions that were inferred from measurements performed using the alkaline elution technique [46,57] and the alkaline agarose gel method [41]. The relative formation of the three classes of DNA damage induced by UVA-irradiation was found to be different from that generated by exposure to gamma rays [58]. First, it has to be remembered that under the latter conditions where ${ }^{\circ} \mathrm{OH}$ radical is the predominant reactive species generated by $\gamma$-radiolysis of water molecules, the yield of endo III- and Fpg-sensitive sites is similar. It may be added that each of the two classes of base damage, namely, oxidized pyrimidine (endo III) and modified purine (Fpg), is generated in about three-fold lower yields than frank DNA strand breaks and/or alkali-labile sites. A similar ratio is observed between the number of endo III-sensitive sites and strand breaks generated in the DNA of UVA-irradiated cells. In contrast, the ratio Fpg-sensitive sites/DNA strand breaks is six times higher upon cell exposure to UVA radiation that after $\gamma$-ray irradiation (Table 2). Interpretation of the overall data requires consideration of the information that is available on the chemical reactions of the putative oxidation processes and reactive species with DNA. It is well established that ${ }^{\circ} \mathrm{OH}$ radical is able to oxidize both purine and pyrimidine bases, whereas its reaction with the sugar moiety through hydrogen abstraction leads in most cases to the formation of strand breaks. One-electron oxidation reactions, guanine being the main target, are likely to be at the best of low significance, mostly due to the fact that most of the putative photosensitizers that are expected to be involved in photooxidative processes are not located in the close vicinity of DNA. Singlet oxygen has been shown to produce exclusively 8-oxodGuo within cellular DNA [32] without inducing detectable amount of strand breaks and FapyGua [33]. Thus, the predominance of damage recognized by Fpg, in fact, mostly 8-oxodGuo, over both DNA strand breaks and endo III-sensitive sites (oxidized pyrimidine bases) may be rationalized in terms of predominant participation of ${ }^{1} \mathrm{O}_{2}(85 \%)$ together with a small contribution of ${ }^{\circ} \mathrm{OH}$ radical (15\%) arising from a Fenton-type reaction. Both the qualitative and quantitative formation of the different classes of oxidative damage to DNA is likely to vary with the nature of the cells since they are expected to contain different types and amount of endogenous photosensitizers. It clearly appears that 8-oxoGua, the main oxidative lesion identified so far in the DNA of UVA-irradiated cells, is at the best generated in very low amounts. In fact, exposure of monocyte cells to a dose of UVA radiation up to $50 \mathrm{~kJ} \mathrm{~m}^{-2}$ is required to double the steady-state level of 8-oxodGuo [58] that arises mostly from oxida- 
tive metabolism in nonirradiated cells. This strongly suggests that the contribution of 8-oxoGua to the overall biological deleterious effects of UVA radiation is low.

Table 2 Base damage and strand breaks induced by UVA radiation and gamma rays to the DNA of human THP1 monocytes ${ }^{\mathrm{a}}$ (from [57]).

\begin{tabular}{lccc}
\hline $\begin{array}{l}\text { Lesions } \\
\text { (per } 10^{9} \text { bases) }\end{array}$ & $\begin{array}{c}\text { Control } \\
\text { (without irradiation) }\end{array}$ & $\begin{array}{c}\text { UVA radiation } \\
\left(\text { per kJ m }{ }^{2}\right)\end{array}$ & $\begin{array}{c}\text { Gamma rays } \\
\text { (per Gy) }\end{array}$ \\
\hline 8-OxodGuo $^{\mathrm{b}}$ & - & 0.98 & 11 \\
FapyGuac $^{\mathrm{c}}$ & - & not determined & 27 \\
DNA strand breaks $^{\mathrm{d}}$ & 265 & 0.9 & 130 \\
Fpg-sensitive sites $^{\mathrm{e}}$ & 190 & 1.9 & 48 \\
Endo III-sensitive sites $^{\mathrm{e}}$ & 195 & 0.3 & 53 \\
\hline
\end{tabular}

${ }^{\mathrm{a}}$ Expressed in number of lesions per either $\mathrm{kJ} \mathrm{m}^{2}$ (dose range $0-150 \mathrm{~kJ} \mathrm{~m}^{2}$ ) or ionizing radiation (dose range $0-40 \mathrm{~Gy}$ ).

bHPLC-ECD.

${ }^{\mathrm{C}} \mathrm{HPLC} / \mathrm{GC}-\mathrm{MS}$.

${ }^{\mathrm{d} C o m e t}$ assay (single strand breaks, double strand breaks, and alkali-labile sites).

${ }^{\mathrm{e}}$ Modified comet assay.

*From [57].

\section{CONCLUSIONS AND PERSPECTIVES}

Recent progress has been made in the elucidation of the main photochemical pathways that are involved in the UVA- and UVB-mediated degradation of cellular DNA. This is mostly due to both a better understanding of mechanistic aspects of photoreactions of DNA model compounds and major improvements of analytical methods aimed at measuring DNA photodamage. Further studies on molecular effects of UVB radiation should focus on photochemical reactions of 5-methylcytosine containing bipyrimidine sequences and deamination process of cytosine residues in dimeric photoproducts both in isolated and cellular DNA. Identification of the endogenous photosensitizers that are involved in the UVA formation of CPDs and 8-oxodGuo, respectively, constitutes another major issue to be addressed. Other possible types of oxidatively generated DNA damage that may be induced by UVA irradiation should also be considered and further investigated. This involves the products that result from addition reactions of malonaldehyde and 4-hydroxy-2-nonenal, two breakdown products of lipid peroxides with aminobases, [59]. DNA-protein crosslinks represent another class of photosensitized DNA photodamage for which there is a strong need of structural and mechanistic information [60]. As a final point, efforts should be made to investigate photochemical reactions of DNA in UV-irradiated human skin. This would be facilitated by improvement in the sensitivity of the HPLC-MS/MS assay, which may involve the use of capillary electrophoresis column.

\section{ACKNOWLEDGMENTS}

This work was partly supported by grants from Institut de Recherche Pierre Fabre and the French Space Agency.

\section{REFERENCES}

1. (a) F. R. de Gruijl. Methods Enzymol. 319, 359-366 (2000); (b) J. C. van der Leun and F. R. de Gruijl. Photochem. Photobiol. Sci. 1, 324-326 (2002); Y. Matsumura and H. N. Ananthaswamy. Toxicol. Appl. Pharmacol. 195, 298-308 (2004). 
2. J. Cadet and P. Vigny. In Bioorganic Photochemistry: Photochemistry and the Nucleic Acids, $\mathrm{H}$. Morrison (Ed.), pp. 1-272, John Wiley, New York (1990).

3. (a) J.-S. Taylor. Acc. Chem. Res. 27, 76-82 (1994); (b) J. Cadet, M. Berger, T. Douki, B. Morin, S. Raoul, J.-L. Ravanat, S. Spinelli. Biol. Chem. 378, 1275-1286 (1997); (c) J.-L. Ravanat, T. Douki, J. Cadet. J. Photochem. Photobiol. B: Biol. 63, 88-102 (2001).

4. (a) A. Fisher-Nilsen, S. Loft, K. G. Jensen. Carcinogenesis 14, 2431-2433 (1993); (b) J. E. Rosen, A. K. Prahalad, G. M. Williams. Photochem. Photobiol. 64, 117-122, (1996); (c) W. G. Warmer and R. R. Weiss. Photochem. Photobiol. 65, 560-563 (1997); (d) E. Kvam and R. M. Tyrrell. Carcinogenesis 18, 2379-2384 (1997); (e) X. Zhang, B. S. Rosenstein, Y. Wang, M. Lebwohl, D. L. Mitchell, H. Wei. Photochem. Photobiol. 65, 119-124 (1997); P. Duez, M. Hanocq, J. Dubois. Carcinogenesis 2, 771-778 (2001).

5. T. Douki, D. Perdiz, P. Grof, Z. Kuluncsics, E. Moustacchi, J. Cadet, E. Sage. Photochem. Photobiol. 70, 184-190 (1999).

6. (a) J. Cadet, M. Berger, T. Douki, J.-L. Ravanat. Rev. Physiol. Biochem. Pharmacol. 131, 1-87 (1997); (b) J. Cadet, T. Douki, D. Gasparutto, J.-L. Ravanat. Mutat. Res. 531, 5-23 (2003).

7. T. Douki, J.-L. Ravanat, D. Angelov, J. R. Wagner, J. Cadet. In Topics in Current Chemistry “Long-Range Electron Transfer in DNA”, G. Schuster (Ed.), Vol. 236, pp. 1-25, Springer-Verlag, Heidelberg (2004).

8. S. Steenken and S. V. Jovanovic. J. Am. Chem. Soc. 119, 617-618 (1997).

9. (a) E. M. Boon and J. K. Barton. Curr. Opin. Struct. Biol. 12, 320-329 (2002); (b) B. Giese. Annu. Rev. Biochem. 71, 51-70 (2002); (c) C. S. Liu and G. B. Schuster. J. Am. Chem. Soc. 125, 6098-6102 (2003).

10. H. Kasai, Z. Yamaizumi, M. Berger, J. Cadet. J. Am. Chem. Soc. 114, 9692-9694 (1992).

11. B. Giese and M. Spichty. ChemPhysChem. 1, 195-198 (2000).

12. S. Steenken. Chem. Rev. 89, 503-520 (1989).

13. T. Douki and J. Cadet. Int. J. Radiat. Biol. 75, 571-581 (1999).

14. L. P Candeias and S. Steenken. Chem. Eur. J. 6, 475-484 (2000).

15. J.-P. Pouget, S. Frelon, J.-L. Ravanat, I. Testard, F. Odin, J. Cadet. Radiat. Res. 157, 589-595 (2002).

16. J. Cadet, M. Berger, G. W. Buchko, P. C. Josh, S. Raoul, J.-L. Ravanat. J. Am. Chem. Soc. 116, 7403-7404 (1994); (b) S. Raoul, M. Berger, G. W. Buchko, P. C. Joshi, B. Morin, M. Weinfeld, J. Cadet. J. Chem. Soc., Perkin Trans. 2 371-381 (1996).

17. V. Shafirovich, J. Cadet, D. Gasparutto, A. Dourandin, N. E. Geacintov. Chem. Res. Toxicol. 14, 233-242 (2001).

18. R. Misiaszek, C. Crean, A. Joffe, N. E. Geacintov, V. Shafirovich. J. Biol. Chem. 31, 32106-32115 (2004).

19. C. Vialas, G. Pratviel, C. Claparols, B. Meunier. J. Am. Chem. Soc. 120, 11548-11553 (1998).

20. J.-L. Ravanat, C. Saint-Pierre, J. Cadet. J. Am. Chem. Soc. 125, 2030-2031 (2003).

21. S. Steenken, S. V. Jovanovic, M. Bietti, K. Bernhard. J. Am. Chem. Soc. 122, 2373-2374 (2000).

22. (a) C. Sheu and C. S. Foote. J. Am. Chem. Soc. 115, 10446-10447 (1993); (b) C. Sheu, P. Kang, S. Khan, C. S. Foote. J. Am. Chem. Soc. 124, 3905-3913 (2002).

23. J. C. Niles, J. S. Wishnok, S. R. Tannenbaum. Org. Lett. 3, 963-966 (2001).

24. W. Adam, M. A. Arnold, M. Grüne, W. M. Nau, U. Pischel, C. R. Saha-Möller. Org. Lett. 4, 537-540 (2002).

25. W. Luo, J. G. Muller, C. J. Burrows. Org. Lett. 3, 2801-2804 (2001).

26. W. Luo, J. G. Muller, E. M. Rachlin, C. J. Burrows. Org. Lett. 2, 613-6164 (2000).

27. (a) Y. Ye, J. G. Muller, W. Luo, C. L. Mayne, A. J. Shallop, R. A. Jones, C. J. Burrows. J. Am. Chem. Soc. 125, 13926-13927 (2003); (b) J.-L. Ravanat, G. R. Martinez, M. H. G. Medeiros, P. Di Mascio, J. Cadet. Arch. Biochem. Biophys. 423, $23-30$ (2004); (c) M. E. Hosford, J. G. Muller, C. J. Burrows. J. Am. Chem. Soc. 126, 9540-9541 (2004). 
28. J.-L. Ravanat, M. Berger, F. Benard, R. Langlois, R. Ouellet, J. E. van Lier, J. Cadet. Photochem. Photobiol. 55, 809-814 (1992).

29. J.-L. Ravanat, C. Saint-Pierre, P. Di Mascio, G. R. Martinez, M. H. G. Medeiros, J. Cadet. Helv. Chim. Acta 84, 3702-3709 (2001).

30. G. R. Martinez, J.-L. Ravanat, M. H. G. Medeiros, J. Cadet, P. Di Mascio. J. Am. Chem. Soc. 122, 10212-10213 (2000).

31. S. Boiteux, E. Gajewski, J. Laval, M. Dizdaroglu. Biochemistry 31, 106-110 (1992).

32. J.-L. Ravanat, P. Di Mascio, G. R. Martinez, M. H. G. Medeiros, J. Cadet. J. Biol. Chem. 275, 40601-40604 (2000).

33. J.-L. Ravanat, S. Sauvaigo, S. Caillat, G. R. Martinez, M. H. G. Medeiros, P. Di Mascio, A. Favier, J. Cadet. Biol. Chem. 385, 17-20 (2004).

34. (a) D. L. Mitchell. In Technologies for Detection of DNA Damage and Mutations, G. Pfeifer (Ed.), pp. 73-85, Plenum, New York (1996); (b) T. Mori, M. Nakane, T. Hattori, T. Matsunaga, M. Ihara, O. Nikaido. Photochem. Photobiol. 54, 225-232 (1991); (c) T. Matsunaga, Y. Hatakeyama, M. Ohta, T. Mori, O. Nikaido. Photochem. Photobiol. 57, 934-940 (1993); (d) L. Roza, K. J. M. Van der Wulp, S. J. MacFarlane, P. H. M. Lohman, R. A. Baan. Photochem. Photobiol. 48, 627-634 (1988).

35. (a) M. Liuzzi, M. Weinfeld, M. C. Paterson. J. Biol. Chem. 264, 6355-6363 (1989); (b) T. Douki, T. Zalizniak, J. Cadet. Photochem. Photobiol. 66, 171-179 (1997).

36. T. Douki, M. Court, S. Sauvaigo, F. Odin, J. Cadet. J. Biol. Chem. 275, 16678-11685 (2000).

37. T. Douki and J. Cadet. Biochemistry 40, 2495-2501 (2001).

38. T. Douki, M. Court, J. Cadet. J. Photochem. Photobiol. B: Biol. 54, 145-154 (2000).

39. (a) T. Douki, J. Cadet. Photochem. Photobiol. Sci. 2, 433-436 (2003); (b) T. Douki, G. Laporte, J. Cadet. Nucleic Acids Res. 31, 3134-3142 (2003).

40. S. Courdavault, C. Baudouin, S. Sauvaigo, S. Mouret, S. Candéias, M. Charveron, A. Favier, J. Cadet, T. Douki. Photochem. Photobiol. 79, 145-151 (2004).

41. T. Douki, A. Reynaud-Angelin, J. Cadet, E. Sage. Biochemistry 42, 9221-9226 (2003).

42. B. Durbeej and L. A. Eriksson. J. Photochem. Photobiol. A: Chem. 152, 95-101 (2002); B. Durbeej and L. A. Eriksson. Photochem. Photobiol. 78, 159-187 (2003).

43. T. Douki, G. Vadesne-Bauer, J. Cadet. Photochem. Photobiol. Sci. 1, 565-569 (2002).

44. R. M. Tyrrell. Photochem. Photobiol. 17, 69-73 (1973).

45. D. Perdiz, P. Grof, M. Mezzina, O. Nikkaido, E. Moustacchi, E. Sage. J. Biol. Chem. 275, 26732-26742 (2000).

46. C. Kielbassa, L. Roza, B. Epe. Carcinogenesis 18, 811-816 (1997).

47. P. J. Rochette, J.-P. Therrien, R. Drouin, D. Perdriz, N. Bastien, E. A. Drobetsky, E. Sage. Nucleic Acids Res. 31, 2786-2794 (2003).

48. J.-H. Yoon, C.-S. Lee, T. R. O'Connor, A. Uasui, G. P. Pfeiffer. J. Mol. Biol. 299, 681-693 (2000).

49. (a) S. E. Freeman, H. Hacham, R. W. Gange, D. J. Maytum, J. C. Sutherland, B. M. Sutherland. Proc. Natl. Acad. Sci. USA 86, 5605-5609 (1989); (b) A. R. Young, C. S. Potten, O. Nikaido, P. G. Parsons, J. Boenders, J. M. Ramsden, C. A. Chadmick. J. Invest. Dermatol. 111, 936-940 (1998); (c) L. A. Applegate, C. Scaletta, R. Panizzon, H. Niggli, E. Frank. Int. J. Mol. Med. 3, 467-472 (1999).

50. S. Courdavault, C. Baudoin, M. Charveron, A. Favier, J. Cadet, T. Douki. Mutat. Res. 556, 135-142 (2004).

51. H. Wei, Q. Cai, M. Lebwohl. Carcinogenesis 19, 1013-1018 (1998).

52. M. S. Stewart, G. S. Cameron, B. C. Pence. J. Invest. Dermatol. 106, 1086-1089 (1996).

53. E. Pelle, X. Huang, T. Mammone, K. Marenus, D. Maes, K. Frenkel. J. Invest. Dermatol. 121, 177-183 (2003). 
54. (a) S. M. Bishop, M. Malone, D. Phillips, A. W. Parker, C. R. Symons. J. Chem. Soc. Chem. Commun. 871-872 (1994); (b) T. Mohammad and H. Morrison. J. Am. Chem. Soc. 118, 1221-1222 (1996).

55. H. J. van Kranen, A. de Lat, J. van der Leun, P. W. Wester; A. de Vries, R. J. W. Berg, C. F. van Kreijl, F. R. de Gruijl. Cancer Res. 57, 1238-1240 (1997).

56. J. Cadet, T. Douki, J.-P. Pouget, J.-L. Ravanat, S. Sauvaigo. Curr. Probl. Dermatol. 29, 62-73 (2001).

57. M. Pfaum, C. Kielbassa, M. Garmyn, B. Epe. Mutat. Res. 408, 137-146 (1998).

58. J.-P. Pouget, T. Douki, M. J. Richard, J. Cadet. Chem. Res. Toxicol. 13, 541-549 (2000).

59. T. Douki, F. Odin, S. Caillat, A. Favier, J. Cadet. Free Radic. Biol. Med. 37, 62-70 (2004).

60. (a) B. Morin and J. Cadet. J. Am. Chem. Soc. 117, 12408-12415 (1995); (b) K. Kurbanyan, K. L. Nguyen, P. To, E. V. Rivas, A. M. Lueras, C. Kosinski, M. Streryo, A. Gonzales, D. A. Mah, E. D. Stemp. Biochemistry 42, 10269-10281 (2003). 